\title{
The Age Factor on Second Language Acquisition and Its Implications for Pedagogy — A Review and Future Research Directions
}

\author{
Fan Yang
}

\begin{abstract}
This study investigates the effects of Age of Onset of Acquisition (AOA) on Second Language Acquisition (SLA) and its implications for pedagogy by drawing upon the empirical evidences provided by recent related studies. The findings show that current research purposes on the AOA issue have been expanded from testing the general AOA effect on SLA to the detailed impact on rate, achievement, nativelikeness of second language learning. Current research also becomes more specific with its language testing domains, including syntax, morphology, phonetics, semantics, and pragmatics. Although major study results agree with the Critical Period Hypothesis (CPH) that AOA effect on SLA exists, it is argued that the effect would differ in terms of different SLA domains, implying the importance and need of a more detailed and specific instructional curriculum for second language education.
\end{abstract}

Index Terms-Age of onset of acquisition, critical period hypothesis, second language education.

\section{INTRODUCTION}

The issue of how the age of onset of acquisition (AOA) might influence one's second language acquisition (SLA) has been one of the most frequently discussed topics in relevant research fields, with numerous books and articles published on this theme [1], [2]. Interests in this "age issue" stem from both theoretical and practical concerns. From the theoretical perspective, studying the age factor helps to support the possible extension of critical period hypothesis from first language acquisition to SLA, and it also answers the question of whether there is still room for an innate faculty to continue working in adulthood. From the practical perspective, investigations on the influence of age on SLA would imply educators the appropriate time to include second language education in the regional or even national curriculum design. In a word, the theoretical and practical benefits of studying the influence of age factor on SLA makes age issue a key research area in relevant fields.

Thus, motivated by the above theoretical and practical driving forces, this paper will examine the impacts of the age factor on second language acquisition with reference to research and articles in the past 10 years on this issue, and it is constructed according to the following outline. First, the key age-related concepts of language acquisition theorists in

Manuscript received April 30, 2018; revised November 2, 2018. This work was supported in part by Glasgow College, University of Electronic Science and Technology of China.

Fan Yang is with University of Electronic Science and Technology of China., Chengdu, 611731 China (e-mail: 1030279158@qq.com). the past few decades will be introduced so as theoretical foundation of this paper. Second, the selection criterion of the papers under review will be presented so as theoretical framework of this paper. Third, this paper will draw upon some of the empirical evidence of the proposed concepts in the area of age research. And, finally, a synthesized conclusion as well as its application for L2 teaching will be summarized.

\section{THEORETICAL BACKDROP}

\section{A. Debates and Positions}

Debates on the age issue in SLA focused on several questions: Is age an essential factor in SLA? If so, how? The younger, the better; or the older, the better? In which aspects of SLA would the age factor be most influential? In the past research history, to answer these questions, especially the second one, several positions have been proposed.

The position of "the younger the individuals involved in L2 learning, the better they would be in learning" coincides with the common belief held by teachers [3]. It is also supported by research on immigrant children's early age of entry into the host country and their successful acquisition of its language [4], [5], as well as research on adults' L2 learning outcomes with various beginning ages [6]. Nevertheless, the hypothesis that "older L2 learners are more successful than younger ones" also finds evidence from empirical studies, especially those in short term and formal instruction setting [7]. In order to adjust the dispute, some other positions have been proposed, like "the younger the better in some respects" and "the younger the better in the long run" positions [2]. As a result, the debates on the influence of AOA on SLA have led to immense theoretical and empirical studies into this research area.

\section{B. Critical Period Hypothesis (CPH)}

\section{1) Definition}

The importance of age factor on language acquisition is then highlighted by the proposal of critical period hypothesis in linguistics by Eric Lenneberg [8]. The critical period, being defined as "the limited phase in the development of an organism during which a particular activity or competency must be acquired if it is to be incorporated into the behavior of that organism" [2], is a biological term then being applied to linguistics stating that the first few years of life should be the crucial time in which an individual could acquire a first language if presented adequate stimuli [8]. Later, researchers 
proposed that this hypothesis might also be applicable in L2 contexts [9], [10].

\section{2) For or against}

The critical period hypothesis (CPH) contradicts with the traditional behavioral approach of language learning, which holds the view that languages are acquired through rewarded imitation of 'language models'. In the opinion of behaviorists, since "new connections between behavior and the environment are formed and reformed throughout life", it is possible for people to gain new skills, including language(s), at any age [11].

Conflicts could also be found between $\mathrm{CPH}$ and Chomsky's universal grammar approach, with the key question being whether the language acquisition device could still be accessible to learners of a second language [12]?

There are also researchers that support this hypothesis. For example, Piaget agreed that there is a certain period that people might be good at acquiring language. However, he argued that rather than abrupt changes in SLA ability after the period, language ability declines gradually with age, coinciding with declines in other cognitive abilities [2]. All in all, both the supporting and opposing voices in CPH help to facilitate the development of AOA related research.

\section{Methodology}

\section{A. Procedures}

As for this study, most of the relevant reports of research that could be located were carefully screened. By searching on Google Scholar and several popular research databases using key words 'Second language Acquisition, Age', 'AOA, Second Language Acquisition'; 'Critical Period, Second Language Acquisition', conferences and journal articles published between January 2009 and June 2018 were located (one in 2005). Included in this study were reports of empirical research involving a direct age-related comparison of L2 subjects and being cited for more than 10 times, with target second languages being not only English, but also other languages like German and Dutch. Excluded in this study were those that compared L1 and L2 participants of ambiguous aged groups, or those that take more than one (no matter age related or not) variables into comparison. Here it should also be noticed that some other past studies might also be mentioned in brief so as to reveal the progress that recent research has made.

The chosen reports were then reread and analyzed. Special attention was paid to such features as research design, study focus, sample size, subject characteristics (L1, educational level, English proficiency), measuring instruments, and the most important, the studies' findings with regard to age related comparisons and their implications for pedagogy.

\section{B. Studies}

There are 18 papers related to Second language Acquisition and the Age effect selected with the searching criteria, as are listed in the table. Nearly one third of them were published within 5 years, and more than $90 \%$ of them were published within 9 years. Some of their findings agree with the $\mathrm{CPH}$, while others do not. The research focuses, design and findings of these studies vary, with the detailed comparison summarized in the table.

TABLE I: STATISTICS OF THE RESEARCHES ON AOA AND SLA

\begin{tabular}{|c|c|c|c|c|c|c|c|c|c|}
\hline \multirow[t]{2}{*}{ REF } & \multicolumn{4}{|c|}{ FOCUS OF STUDY } & \multicolumn{4}{|c|}{ RESEARCH DESIGN } & \multirow{2}{*}{$\begin{array}{l}\text { SUPPORT } \\
\mathrm{CPH}\end{array}$} \\
\hline & F1 & $\mathrm{F} 2$ & F3 & F4 & D1 & D2 & D3 & D4 & \\
\hline [13] & & $\checkmark$ & & & & $\checkmark$ & & & $\checkmark$ \\
\hline [14] & & & $\checkmark$ & & $\checkmark$ & & & & $\checkmark$ \\
\hline [15] & & & $\checkmark$ & & & & & $\checkmark$ & $\checkmark$ \\
\hline [16 & & & $\checkmark$ & & & & & $\checkmark$ & $\checkmark$ \\
\hline [17] & & & & & & & $\checkmark$ & & \\
\hline [18] & $\checkmark$ & & & & $\checkmark$ & $\checkmark$ & $\checkmark$ & & $\checkmark$ \\
\hline [19] & & & $\checkmark$ & & & $\checkmark$ & $\checkmark$ & & \\
\hline [20] & & & $\checkmark$ & & & $\checkmark$ & $\checkmark$ & & \\
\hline [21] & & & $\checkmark$ & & & $\checkmark$ & $\checkmark$ & & \\
\hline [2] & & & $\checkmark$ & & & $\checkmark$ & & $\checkmark$ & $\checkmark$ \\
\hline [23] & & & & $\checkmark$ & & & $\checkmark$ & & $\checkmark$ \\
\hline [24] & & & & & & & $\checkmark$ & & $\checkmark$ \\
\hline [25] & & & $\checkmark$ & & & $\checkmark$ & $\checkmark$ & & \\
\hline [26] & & $\checkmark$ & & & & $\checkmark$ & & & \\
\hline [27] & & & $\checkmark$ & & $\checkmark$ & & & & $\checkmark$ \\
\hline [28] & & $\checkmark$ & & & $\checkmark$ & & & & $\checkmark$ \\
\hline [29] & & & $\checkmark$ & & & & & $\checkmark$ & $\checkmark$ \\
\hline [30] & & & & $\checkmark$ & & & & $\checkmark$ & $\checkmark$ \\
\hline
\end{tabular}

F1=rate of L2 learning, F2= nativelikeness of L2 learning, F3= achievement of L2 learning, F4=process of L2 learning.

D1=Syntax, D2=Phonetics, D3= Morphology, D4=Semantics

\section{FINDINGS}

In the 51 years since the publication of Lenneberg's [8] original essay, there has been a proliferation of work on the topic of AOA. However, the $\mathrm{CPH}$ debate consists and remains to be unsolved in current studies. What is new is that based on present updated scientific technologies as well as communication convenience, the studies in recent years continued their exploration on the AOA issue with more focused research areas (syntax, morphology, phonetics, semantics and pragmatics) and varied research design.

\section{A. Analysis of AOA Effect on Syntax}

Syntactic proficiency is a standard and important criterion in measuring second language learners' L2 proficiency, since grammatical knowledge reveals one's comprehension and construction of the systematic framework and rules of the target language. In addition, the abundance of several accessible and acknowledged research instruments for language learners' syntactic proficiency also makes syntax a popular research sample. As a matter of fact, a few syntactic research instruments have already become the prototypical measurement of AOA related studies, like the grammaticality judgment test (GJT) [13]. Relying on these countable research tools, current research expands from testing the general AOA effect on SLA to the detailed AOA effect on rate [14], achievement [15], nativelikeness [16] of L2 learning, with most of the current findings agree with the CPH (e.g. [15]). And these studies reported that no matter what kind of L1 (Russian, English, Spain) and L2 (English, German, Swedish) are the participants involved, in general (100\% supporting $\mathrm{CPH}$ from Table I), AOA factor is negatively correlated with syntactic proficiencies like definitions and analogies, while a less obvious correlation is observed between AOA effect and verbal reasoning [13]. Thus, a more significant focus on the teaching of L2 grammar at an early age is suggested.

\section{B. Analysis of AOA Effect on Phonetics}


Studies on AOA effects show that phonetic proficiency in the target language is among the most difficult knowledge to acquire for late learners. Previous investigations have consistently demonstrated that post-puberty learners were detectably different in speech production from early L2 learners, no matter in what kind of L1 contexts [12], [17]. With improved phonetic testing devices and methods, current research continued to examine this proposal by setting the research contexts on L2 languages like Swedish [18], French [19], English [20], [21], and by involving participants whose AOA vary from 1-47 [22], 3-12 [19], 15-63 [18], 8-18 [20], 19-35 [21], 3-6 [23] years old. Some of their results agree with the $\mathrm{CPH}$, while others not $(62.5 \%$ against $\mathrm{CPH}$ from Table I). However, here a strange trend is observed: it seems that most studies that agree with the $\mathrm{CPH}$ set their participants' AOA range in a much bigger scope (e.g. 1-47; 15-63 years old), while those whose results are against the CPH set the participants' AOA range in a smaller scope (e.g. $3-12 ; 8-18 ; 19-35$ years old).

In terms of progress, these studies report a more detailed distinction on the AOA effects on phonetics-nativelikeness of L2 acquisition is more influenced than the process, and pronunciation accuracy, accent and tone are the most difficult skills to command for late L2 learners [20]. What is more, Huang and Jun's study in 2009 [24] shows that for much more culturally-bound areas like the phonetics in prosody, post-puber L2 learners might perform distinctly worse than early learners. Therefore, these studies suggest that the incorporation of pronunciation features must be a priority in the L2 teaching syllabus, and this should start as early as possible.

\section{Analysis of AOA Effect on Morphology}

In the previous AOA studies, more focus might have been put on the age effect on grammar accuracy and pronunciation, morphology is the less touchable research area. In fact, it has never been tested separately-most times combined with syntax in the grammaticality judgment tests to test subjects' comprehension and production of grammatical knowledge [14]. However, in recent interdisciplinary research, some AOA studies began to borrow instruments like event-related brain potentials test from psycholinguistics to explore subjects' information processing course in the morpheme level [25], [26]. One piece of research done by Babcock [27] on different AOA categorized English L2 immigrants' handling of inflected forms has revealed that higher AOA would lead to less proper usage and memory of morphemes like past tense. For ultimate attainment concern, it is also indicated that an early start in L2 education would reduce possible frequent interlanguage obstacles in the future.

\section{Analysis of AOA Effect on Semantics}

Like morphology, semantics is the less focused research area. Current research [28]-[30] began to fill in this gap, with nearly all of the studies supporting CPH (100\% from Table I). One typical example is Isel's [28] magnetic resonance study which addressed to the effect of neural maturation on the attainment of lexical knowledge in L2 through a cross-linguistic neural adaptation paradigm. By observing the mental activity of L2 learners perceiving concrete nouns, Isel's research aimed to tap cognitive processes at the semantic-conceptual level of processing. The results indicate that as for grammatical knowledge, the attainment of lexical knowledge in L2 is affected by neural maturation, with late L2 learners being affected more by the L1 lexical knowledge transfer. However, there are still too few studies to suggest its implication for educational purposes.

\section{E. Changing Research Design}

As have been mentioned by Singleton and Ryan [2] in their review, the past research on AOA and SLA focused on subjects that are immigrants or short-period adult academic English learners. However, in recent years, as a result of scientific progress and intercultural communication, "dominant" languages like English spread across the globe. Thus, second language learners are not limited within immigrants or academic staffs. In several regions, bilingual education programs and formal bilingual instructional schools became popular. Intrigued by this phenomenon, current researches also began to focus more on subjects who acquire second language through explicit instructional learning rather than immigrants who acquire the target language through implicit learning or adult academic learners [14], [21]. What is more, a shadow impact of combining formal second language education with AOA research is that it helps to facilitate the instructional curriculum of these education programs. Apart from research context, recent studies also began to seek for the help of newly updated scientific equipment and interdisciplinary experiment designs, as above discussion has illustrated.

\section{IMPLICATION}

\section{A. Research}

The foregoing review of studies suggests a need for more rigorous and balanced research in this area. Future research should be detailed enough to test on every specific area of study in the sub-domains of AOA effect research, so as to see whether the AOA effect on L2 learning would differ in terms of different subdomains. If time and effort allow, it should also be comprehensive enough to cover each participant so that the findings of the study would not differ due to possible difference in research design and subjects, as has been suggested in the phonological part.

In addition, future research should also take into consideration variables like length of residence (LOR) and the age being tested in research designs, for this kind of time factor similar to AOA could also have a probable influence on the research findings.

More research areas should be expanded. At present, more focus was put on syntax and phonetics, while research fields like semantics are also worth noticing, and more culturally-bound research areas like pragmatics are also in need of further investigation. Empirical studies on how different educational policies with different L2-starting-age requirements have influenced the learners' general language proficiency, as well as the detailed curriculum design and how different language domains should be focused in different periods of learning phrase could be conducted.

\section{B. Practice}

The current development of AOA research implies that a 
more detailed instructional curriculum for L2 learning and teaching is necessary. For L2 learners of varied ages, different learning and teaching schedule should be made. For areas where late learners are found to be apparently less skilled in compared with early birds, more focus and time should be paid, and vice versa. For learners themselves, they should understand that an age effect exists in their L2 learning, and the effect might differ concerning different domains. Furthermore, parents and teachers should notice that in general, it is better to start L2 learning earlier than later, for in areas like phonetics, few post-puber learners might succeed in achieving a nativelike proficiency.

\section{CONCLUSION}

Before critical period hypothesis was introduced to second language acquisition studies, it is simply idle theorizing to suggest that language learning should consider the age factor, for it is just a common belief held by some language teachers, and more focus might have been located to other factors like learning duration (length of residence, LOR) and context. However, recent research has shown that the starting age does affect one's second language acquisition. As the above review and discussions have illustrated, the AOA effect on SLA exists and it would differ in terms of different SLA domains. In addition, the discussion also reminds current researchers that more attention and efforts should be paid on critical period hypothesis studies, and teachers and parents should also notice the unique benefits of early second language education. Though the critical period is just a matter of time, as the saying goes, time flies, time is money, and time makes proficiency!

\section{ACKNOWLEDGMENT}

Fan Yang thanks her colleagues in Glasgow College, UESTC, and also the Dean Professor Zeng, the Deputy Dean Professor Liu, Secretary Mr. Gao, and Deputy Secretary Ms. He for their kind help.

\section{REFERENCES}

[1] D. Birdsong, "Second language acquisition and the critical period hypothesis," Routledge, 1999.

[2] D. M. Singleton and L. Ryan, "Multilingual matters," Language Acquisition: The Age Factor, vol. 47, pp. 28-32, 2004.

[3] M. Kirch, "At what age elementary school language teaching?" Modern Language Journal, vol. 40, pp. 399-400, 1956.

[4] J. Asher and R. Garcia, "The optimal age to learn a foreign language," Modern Language Journal, vol. 53, pp. 41-334, 1982.

[5] S. Oyama, "The sensitive period and comprehension of speech," Working Papers on Bilingualism, vol. 16, pp. 1-17, 1978.

[6] B. Harley and D. Hart, "Language aptitude and second language proficiency in classroom learners of different starting ages," Studies in Second Language Acquisition, vol. 19, no. 3, pp. 379-400, 1997.

[7] J. J. Asher and B. S. Price, "The learning strategy of the total physical response: Some age differences," Child Development, pp. 1219-1227, 1967.

[8] E. Lenneberg, The Biological Foundations of Language, New York: Wileyand Son, 1967.

[9] C. E. Snow et al., "The critical period for language acquisition: Evidence from second language learning," Child Development, vol. 49, no. 4, pp. 1114-1128, 1978.

[10] S. D. Krashen et al., "Age, rate and eventual attainment in second language acquisition," Tesol Quarterly, pp. 573-582, 1979.

[11] A. Moyer, "Ultimate attainment in L2 phonology," Studies in Second Language Acquisition, vol. 21, no. 1, pp. 81-108, 1999.
[12] R. DeKeyser, I. Alfi-Shabtay, and D. Ravid, "Cross-linguistic evidence for the nature of age effects in second language acquisition," Applied Psycholinguistics, vol. 31, no. 3, pp. 413-438, 2010.

[13] J. MacSwan and L. Pray, "Learning English bilingually: Age of onset of exposure and rate of acquisition among English language learners in a bilingual education program," Bilingual Research Journal, vol. 29, no. 3, pp. 653-678, 2005.

[14] N. Fullana and J. C. Mora, "Production and perception of voicing contrasts in English word-final obstruents: Assessing the effects of experience and starting age," Recent Research in Second Language Phonetics/Phonology, pp. 97-117, 2009.

[15] R. V. Reichle, "Judgments of information structure in L2 French: Nativelike performance and the critical period hypothesis," IRAL-International Review of Applied Linguistics in Language Teaching, vol. 48, no. 1, pp. 53-85, 2010.

[16] T. Bongaerts, B. Planken, and E. Schils, "Can late starters attain a native accent in a foreign language? A test of the critical period hypothesis," The Age Factor in Second Language Acquisition, pp. 30-50, 1995.

[17] N. Abrahamsson, "Age of onset and nativelike L2 ultimate attainment of morphosyntactic and phonetic intuition," Studies in Second Language Acquisition, vol. 34, no. 2, pp. 187-214, 2012.

[18] A. A. MacLeod and C. Stoel-Gammon, "What is the impact of age of second language acquisition on the production of consonants and vowels among childhood bilinguals?" International Journal of Bilingualism, vol. 14, no. 4, pp. 400-421, 2010.

[19] H. Hopp and M. S. Schmid, "Perceived foreign accent in first language attrition and second language acquisition: The impact of age of acquisition and bilingualism," Applied Psycholinguistics, vol. 34, no. 2, pp. 417-417, 2013.

[20] K. Saito and F. X. Brajot, "Scrutinizing the role of length of residence and age of acquisition in the interlanguage pronunciation development of English/../by late Japanese bilinguals," Bilingualism: Language and Cognition, vol. 16, no. 4, pp. 847-863, 2013.

[21] N. Abrahamsson and K. Hyltenstam, "Age of onset and nativelikeness in a second language: Listener perception versus linguistic scrutiny," Language Learning, vol. 59, no. 2, pp. 249-306, 2009.

[22] J. Granfeldt, "The development of gender in simultaneous and successive bilingual acquisition of French-Evidence for AOA and input effects," Bilingualism: Language and Cognition, pp. 1-20, 2016

[23] B. H. Huang and S. A. Jun, "Age effect on the acquisition of second language prosody," presented at the 33rd Boston University Conference on Language Development, 2009.

[24] M. G. Dowens, M. Vergara, H. A. Barber, and M. Carreiras, "Morphosyntactic processing in late second-language learners," Journal of Cognitive Neuroscience, vol. 22, no. 8, pp. 1870-1887, 2010.

[25] K. Steinhauer, E. J. White, and J. E. Drury, "Temporal dynamics of late second language acquisition: Evidence from event-related brain potentials," Second Language Research, vol. 25, no. 1, pp. 13-41, 2009.

[26] L. Babcock, J. C. Stowe, C. J. Maloof, C. Brovetto, and M. T. Ullman, "The storage and composition of inflected forms in adult-learned second language: A study of the influence of length of residence, age of arrival, sex, and other factors," Bilingualism: Language and Cognition, vol. 15 , no. 4, pp. 820-840, 2012.

[27] F. Isel, A. Baumgaertner, J. Thrän, J. M. Meisel, and C. Büchel, "Neural circuitry of the bilingual mental lexicon: Effect of age of second language acquisition," Brain and Cognition, vol. 72, no. 2, pp. 169-180, 2010.

[28] M. Haiyan, "Age of acquisition effects in Chinese EFL learners' Delexicalized Verb and Collocation Acquisition," International Journal of Applied Linguistics and English Literature, vol. 4, no. 3, pp. 189-197, 2015.

[29] J. Shen, "Age factors in second language acquisition: A case in China," Overseas English, vol. 16, pp. 105, 2017.

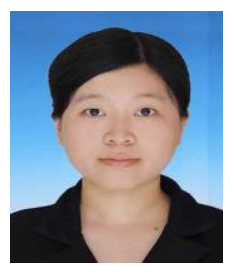

Fan Yang was born in China in 1992. She got her master degree at the Chinese University of Hong Kong and her bachelor degree at Beijing Normal University. Her major field of study is second language teaching and second language acquisition.

She is a lecturer in Glasgow College, University of Electronic Science and Technology of China. She is also an honorary lecturer at University of Glasgow. She had rich experience in the teaching practice of engineering English and English for academic purposes. 